\title{
How to Become a "Real Chicagoan" in No Time: The Promise and Pedagogy of Walking Tourism
}

\author{
Jacob Henry* \\ Department of Anthropology, Memorial University of Newfoundland, St. John's, NL, CANADA \\ Student:jlhenry@mun.ca*
}

\begin{abstract}
This study takes seriously the tourist's desire to feel like a local and examines how walking tour guides work toward fulfilling that desire. The paper examines some of the techniques used by urban walking tour guides to convey local cultural cues. The tourist, armed with these cues, may feel able to fit into a new culture as a quasi-insider. Through qualitative methods, primarily participant observation, the researcher identifies three tactics that guides implement to make the tourist to feel like a local. These tactics are labeled agent alignment, urban alchemy, and material action. These tactics take place within a borderzone, the liminal time-space between insider and outsider status. A successful guide facilitates the border crossing, allowing the tourist to transition from tourist to perceived 'real Chicagoan.' However, the unsuccessful guide forces tourists to exit the borderzone unchanged, still as tourists. These findings highlight the uniqueness of walking tourism as a niche tourism and wade into the conceptual milieu of 'localism' and 'the local.'
\end{abstract}

\section{KEYWORDS}

Walking Tourism; Urban Tourism; Tour Guides; Localization; Interculturalism; Urban Alchemy; Agent Alignment; Chicago

\section{INTRODUCTION}

The tourists, a class of design students from a Mississippi university, huddled around their guide, Gerry. Backed by the grand marble staircase of the Chicago Cultural Center, Gerry (pseudonyms throughout) might have seemed somewhat muted in his earth tone, untucked button-down shirt, cargo pants, and well-worn baseball cap. However, as he began his well-rehearsed prose, using a thicker-than-normal Chicago accent, he commanded the tourists' attention. First, Gerry boasted about the quality of his start-up touring company: "we are the number one on TripAdvisor walking tours in Chicago," (they aren't). He then proselytized on Chicago's importance to the fields of architecture, music, and food and described how Chicago could only be understood as a mosaic of neighborhoods. Casually gesturing to the staircase behind him, Gerry told the tourists that the Cultural Center was the gateway to Chicago and that both the building and the city are places the tourists would not forget. Once he finished with the introduction to the city, Gerry paused for a moment, seeming to reflect on the task he and these tourists were about to undertake. After a beat, as if to size up the seriousness of this particular group, he offered the tourists the critical promise, "if you ask questions and pay attention, you'll become a real Chicagoan in no time."

This study explores how Gerry's guides try, with varying success, to fulfill the promise of turning tourists into 'real Chicagoans.' Tour guides in Chicago intuitively know to include the promise of 'realness' in their half-day neighborhood walking tours. They, and the many websites and apps competing with them for tourist attention, ${ }^{1-3}$ understand that tourists, especially walking tourists, want to transcend 'being tourists' by 'becoming local.' The guides serve as gatekeepers to a knowledge about the city, a type of symbolic capital (in lay terms, insider knowledge) ${ }^{4}$ that the tourists access through participation in ritual. Tourism, as Crick recognized long ago, is an act of transfer: economic capital turns to cultural capital. ${ }^{5}$

What does it mean to be a 'real Chicagoan?' The tourists certainly do not gain a deep understanding of a locality's cultural fabrics and economic anxieties after a morning tour in a neighborhood. There is no assertion that the tourists actually become local in the most literal sense. Instead, guides attempt to instill a local competence; the tourist should feel enlightened, intrigued, and better able to fit into a local situation than when the tour began. The tourist, armed with cultural cues, may feel like an insider for the remainder of their stay and on subsequent visits to the city. This process can be conceptualized as the transmission of a most basic, simplified habitus of a neighborhood or city. Traditionally, habitus is used to describe a "quasi-conscious" mental operation in which behavior and norms are predisposed based on social structures. ${ }^{6}$ The caricatured habitus of walking tours skips the structural cause and jumps right to the predisposition effect; the tourists are taught to frame their behavior by asking how a real Chicagoan might approach a given situation. That is, they are empowered to make strategic calculations based on their understanding of 'Chicago habitus' --at least that is the guide's hope. 
To date, scholarly writing on 'becoming local,' acquiring some level of habitus, has primarily focused on international tourism. Backpackers in India want to blend into the toured community ${ }^{7}$ and international conservation volunteers in Thailand want to live the 'Thai way." However, Gerry's promise in the domestic tourism context remains largely unexplored. To gather data, the researcher conducted participant observation on multiple walking tours in Chicago neighborhoods. The subsequent analysis revisits classic concepts in tourism studies like the borderzone and authenticity, framed within the context of domestic walking tourism. The researcher will also show how at least three touring tactics need to be successfully implemented for the guide to facilitate the crossing from tourist to 'real Chicagoan.' Agent alignment describes how guides position themselves relative to the toured community and the tourists. Urban alchemism is adapted for the current study to describe how guide metanarratives shape the urban landscape and how the guides help tourists make sense of the city. Material action is the process in which guides utilize movement, physicality, and material consumption to supplement the touristic metaphor of border crossing from tourist to 'real Chicagoan.'

Two tours are presented as case studies. One tour, led by Alex, was by all accounts successful. The tourists smiled, took ample photographs, and asked questions that proved they were engaged with Alex's narrative. At the end of this tour, Alex employed a rhetorical device (see below) which suggested the tourists had successfully 'become local.' Another tour, led by Fred, yielded different results and is presented here as a cautionary tale. On this tour, the tourists seemed disengaged, distant, and occasionally antagonistic toward their guide. Fred was unable to transmit the cultural cues needed to enlighten the tourists or to see them invested in the locality. While each tour operated in a unique context with unique tourists, the (in)ability of the guide to facilitate the crossing to 'real Chicagoan' likely contributed to the varying end results.

\section{METHODS}

Tourism in Chicago is big business. In 2015, over 50 million tourists visited the city. This generated $\$ 935$ million in tax revenue. ${ }^{9}$ The same year, Chicago was ranked as the $9^{\text {th }}$ most internationally-visited American city. It also consistently ranks in the top ten domestically-visited cities and is often the only Midwestern city on such lists. ${ }^{10}$ Such an impressive tourist presence encourages entrepreneurship among locals who spin their own narratives and start their own tour companies. Gerry founded Out and About Chicago after retiring and now makes it his primary business to share Chicago with others.

Out and About employs fifteen guides, all of whom have come to tourism from other professions. Many are retired and some maintain other, more substantial, employment. Because most of the guides treat their work with Out and About as hobby-like rather than necessary employment, they tend to only work tours as their schedules allow. While Gerry works almost every tour, the other guides are interchangeable topical generalists. The exceptions to this are Out and About's gastro-tourism specialists and an architecture guide. The company offers about a dozen highly customizable tours, some are in Chicago's downtown Loop and others are in the city's neighborhoods. Personal tours can be booked for $\$ 25$ to $\$ 40$. Group discounts are offered to schools and corporate organizations. Both tours showcased in this study were school groups and presumably were offered these discounts.

At the beginning of each observed tour, Gerry delivered an opening monologue giving the tourists a brief overview of what was to come. After Gerry's introduction, the large tour groups were divided into subgroups of about ten people and matched with a guide. One tour showcased in this study took place in the downtown Loop and the other occurred in the Mexican-American enclave, Pilsen. Each tour lasted a few hours, the better part of a morning, and ended at the group's pre-determined lunch location. The guides did not reconvene after the tour was completed. Both tours covered about a mile of ground in mild Fall weather, which seemed comfortable to the researcher. However, during post-tour reflection, both guides indicated that the routes had been too long and planned to ask Gerry to shorten them for future tours.

The Loop tour was presented by Alex, a middle aged attorney who became a "certified" Chicago tour guide after he moved to the city from Los Angeles ten years ago. His resume includes work with the Cultural Center of Chicago and Gerry describes him as a, "virtual encyclopedia of contemporary and historic Chicago." Alex chose to work with Gerry and Out and About Chicago after his main career as a lawyer "took off" and demanded more of his time. Out and About's small business style allows Alex to keep guiding, which he enjoys, and practice law. The tourists on this tour were college students enrolled in a design program at a large Mississippi university; they were spending a week in Chicago studying skyscraper architecture and art. The professors leading the trip knew Gerry and had used Out and About for their bi-annual field trip for as long as they could remember. Both of the professors were complimentary of Gerry, Alex, and the entire experience with Out and About.

The Pilsen tour was led by Fred, a retired teacher who claims he, "didn't want to give up teaching, [he] just wanted to give up grading papers." Fred taught and still resides in the suburbs. While he did teach courses on Chicago, he has never lived within city limits. Fred seemed unfamiliar with the Pilsen tour; he carried a white plastic binder which contained a written version of the tour and referenced it liberally. He is proudly of Irish heritage, and while Pilsen was never predominantly inhabited by Irish immigrants, he frequently brought them into the narrative as exemplarily of the immigrant struggle. The tourists were high school 
students from a northwestern suburb who were enrolled in a Spanish class. The school was affiliated with the Catholic Church and the students were all in uniform. Teachers and classroom aides also walked along with the group as chaperones. These adult tourists' behavior and level of engagement was similar to that of their students.

The researcher, in a sense, was also a tourist. Participant observation allows the body of the researcher to become the instrument of data collection. ${ }^{11}$ Thus, in addition to recording the actions of the tourists, the researcher too felt the excitement, lulls, boredom, and shock on tour. While the researcher's own feelings are not foregrounded in this analysis, they undoubtedly inform it.

During ethnographic fieldwork, a researcher hopes the observed group will conduct business as usual, avoiding what is commonly referred to as the Hawthorne effect. ${ }^{11}$ This normalcy is typically acquired through building rapport, but given the transitory nature of tourism, the best that could be achieved for the current project was innocuity. The researcher walked at the back of the group and did not initiate any interactions with the student-tourists and only briefly spoke with their instructors. Neither the researcher nor the tour guides noted any major changes in tourist behavior due to a researcher's gaze, though this possibility cannot be totally ruled out. After the initial introductions in which Gerry presented the other tour guides and the researcher (along with his academic affiliation and the erroneous fact that he was a graduate student) to the tourists, they more or less ignored the research process. In order to constantly remind the tourists that they were being studied, the researcher wore clothing with recognizable branding from his academic institution. The tourists could also see the researcher making jottings in a notebook. ${ }^{12}$ After each tour, these jottings were converted and expanded into what Bernard calls analytic and descriptive field notes. ${ }^{11}$ This project utilizes notes from about fifteen hours in the field observing tour groups and conversing with Gerry. The project design was preapproved by Gerry as well as professors at Elmhurst College. While the institution lacks an official IRB process, this independent research was supported by the College and department.

Finally, taking cues from newer forms of research such as participant action research, ${ }^{13}$ initial research findings were shared with Gerry, who was enthusiastic to learn about the process. The main theme of these conversations was representation in Pilsen. Gerry confessed that he has always been uncomfortable giving tours in Pilsen but could not understand the reasons for this affective reaction. After lengthy conversations, the researcher suggested that Gerry's discomfort may arise from controlling the narrative about a group of people, Mexican-Americans, to which he does not belong. Gerry readily agreed that such representation is problematic. He realized that in other neighborhoods he could use his own lived experience, whereas in Pilsen he had to rely on "their" experience. When asked why he did not hire Pilsen residents to give the tour, he was quick to say that he had done so in the past but it, "hadn't worked out." This conversation concluded with the researcher recommending Gerry approach a non-profit student housing complex in the neighborhood with a position offer. However, over a year after the fieldwork concluded, Out and About's website does not indicate this hire was made.

\section{LITERATURE REVIEW}

The question of who tourists are and what they want has intrigued scholars for the last fifty years. While some scholars believe that tourists search for the real lived experience of the toured ${ }^{14}$ others propose that tourists want to invert their regular lives in order to temporarily play a queen or peasant. ${ }^{15}$ Other scholars propose that tourists simply want to have fun, preferably in an individualized, hyper-realistic setting. ${ }^{16}$ In a critical paper to tourism studies, Erik Cohen acknowledges that all these positions have some empirical support but 'tourists' as a homogenous group do not exist. ${ }^{17}$ Cohen proposed a typology to categorize tourists by their level of integration into local life. This model attempted to account for all tourists, from those who just want a distraction from their jobs to those who search for profound experiences. Bruner also found differentiation between tourists, recognizing that sites with wide appeal attract people with varying expectations. ${ }^{18}$ However, after conducting multi-sited ethnographies, Bruner noted that tourists with similar demographics and characteristics seem to self-delineate by type-of-tourism and venue. ${ }^{19,20}$

Urban walking tourists seem to be somewhat delineated from other categories. Most notably, walking tourists blur the distinction between local and tourist. They are often domestic tourists, sometimes even from the same city or the nearby suburbs. ${ }^{21,22}$ To them, tourism is educational and cultural work. They want to understand the city on a deeper level and gain the cultural cues to move beyond the tourist bubble (in their own home). These tourists resemble what Butcher termed 'New Moral Tourists.' They are like amateur anthropologists who are self-aware enough to realize that they, the tourists, have an impact on the places they visit and thus they tread lightly in order to respectfully study the local culture they enter. ${ }^{23}$ The grounded nature of urban walking tourism is seen as a perfect option for metro residents and tourists from further afield to access areas of a city that seem complex, unfamiliar, or intimidating ${ }^{24}$ while also avoiding the massive touristic industries that are perceived to destroy the environments they extol. ${ }^{23}$ To maintain the classic binary of the tourist at play and the host at work ${ }^{5}, 25$ may not provide a complete picture of walking tourism. Instead, while the tourists are studying hard, their guides ${ }^{26}$ and the random locals on the street who 'contribute' to tours ${ }^{27}$ are sometimes less than serious and may poke fun at the contrived nature of the touristic situation. 
New Moral Tourists are reflective and critical learners, when prompted. ${ }^{20}$ They are the newest iteration of tourist-learners in long history of tourism-as-overt-pedagogy. From the Grand Tour ${ }^{16}$ to today, sites have been designed to accommodate schoolchildren and thus serve an overt educational function. ${ }^{18}$ Walking tourism is especially well-suited to create a pedagogy of the city. ${ }^{27}$ Many guides believe they are providing a public service by spreading niche knowledge as public historians. ${ }^{30}$ They frame the encounter between tourist and toured and often teach a celebration of difference and localism.22 Thus, walking tour guides' urban alchemism (see below) is always an act of pedagogy, even without formal students, as it teaches the tourists a way to know the city. While some scholars question whether tourism is a just instrument of education, ${ }^{28}$ it continues to be a complex form of cultural transmission. It is not unusual for walking tours to serve as school-sanctioned pedagogical field experiences and overlap with institutional education at all levels. ${ }^{27,29}$

The discussion of 'real Chicagoans' requires a brief foray into one of the most enduring themes in tourism literature: authenticity. In a much citied work, Dean MacCannell suggests that it is every tourist's quest to find life as it is authentically lived in the tourist destination. However, the tourist will always fail to find the true 'backstage' lived experience of the toured community. ${ }^{31}$ In this view, the world of tourism is divided into public and private spaces for the tourist to navigate. Authenticity is juxtaposed with superficiality and whatever is easily accessed by the tourist is inauthentic. ${ }^{32}$ Cohen and Cohen take a different view, asserting that authentication is an ongoing process, not an innate quality. Sites can be authenticated based on emotions and beliefs of the tourists (hot authentication) and also based on official agencies' and academics' recommendations (cool authentication). ${ }^{33}$ This means that authenticity is often contested and disputes between the 'from below' and 'from above' authentication sources are common. Bruner expands the discussion of contestation by suggesting there are at least four meanings of authenticity. Sites may be authentic if they are recognized by so-called locals; by the tourists who imagine the site; if they are originals, not reproductions; or if they are 'coolly authenticated' by authoritative agencies. ${ }^{18}$ Bruner is generally more critical of authenticity than Cohen - he adopts a constructivist approach that rejects the notion that there is a hidden 'real' version of the toured culture. ${ }^{34}$ Instead of asking what makes a 'real Chicagoan' he might ask who makes the 'real Chicagoan,' paying special attention to the struggle over the interpretations of emerging cultural discourse. ${ }^{18}$ The culture on tour is real. The tourists, the toured, and the tourism in which they engage are real. Authenticity, to Bruner, is not a debate over front and backstage but rather it is about the socio-political processes which brought both cultures to this particular display. ${ }^{20}$

Becoming a 'real Chicagoan' certainly must include celebrating the small and seemingly insignificant characteristics that make the city unique. ${ }^{22}$ Walking tourists are quite literally putting feet to pavement as they explore 'localized' urban areas. They breathe the air of the city and bump elbows with locals on crowded sidewalks. The tourists gaze and are gazed upon as they become part of the urban landscape. This contrasts with other forms of urban mass tourism, like bus tours, which are more confining and sterile experiences. ${ }^{30}$ By getting the tourists 'out amongst the folks' (folks who sometimes interrupt tours), guides present a city that would be recognizable to locals, as it is imagined by the tourists, and in a non-simulated form. While guides may 'schmaltz' the stories or add small embellishments, the Chicago of the walking tours is usually authentic. ${ }^{18,27}$ Walking tourism with a political message may even take up the same questions about cultural constructivism as Bruner and act as a space of dissent against hegemonic narratives of place. ${ }^{35}$ Even walking tour guides who partner with institutions of cultural production are often independent contractors who play at the boundaries of cool authentication and socially sanctioned cultural narratives. ${ }^{21}$

Recently, scholars have asked, with some alarm, why tourists continue leave home when cultural amenities and opportunities are often available in their home cities. ${ }^{36,16}$ This concern seems especially relevant for the urban tourism sector. The post-modern cityscapes of North America supposedly blend together; they are themed and simulated so that the world can be represented in compact spaces, even within a single mall. ${ }^{16,37}$ Why visit the original Chicago, the post-modern argument goes, when you can have a better, simulated Chicago in your hometown? Walking tour guides fight this de-differentiation by emphasizing the important and unique cultural features, beyond the simulacra, of their localities. Their stories, their livelihoods, and arguably portions of their identity are bound to the premise that real, not just hyper-real, places are worth teaching and exploring. These tours turn urban features that may seem ordinary or homogenized into moments of localized meaning. ${ }^{35} \mathrm{It}$ is not the showcasing of simulation that makes walking tourism interesting, it is the pedagogical nature of 'becoming local' which promises the tourist something they cannot get from theme parks: it is this promise and pedagogy that entices walking tourists to leave home, even in the post-modern era.

\section{DISCUSSION}

MacCannell's frontstage-backstage is not as helpful for understanding Gerry's promise as Bruner's concept of the borderzone. The walking tourists do not move continually toward a more authentic version of the toured, but rather enter and attempt to successfully cross a metaphorical borderzone, the liminal time-space between tourist and local babitus. According to Bruner, the borderzone exists both as a moment within reality but also as a theatrical imaginary with a defined beginning and end. ${ }^{20} \mathrm{In}$ Bruner's classic example, the Maasai transform themselves from villagers to colorful performers to entertain tourists. The tourists 
are mobile and their presence initiates the 'point of conjuncture' while the Maasai are seen as permanent fixtures of the Kenyan landscape. ${ }^{34}$

In walking tourism, every tour occurs in the borderzone. The tourist begins the tour (enters the border) as an outsider, a nonmember of the physical and social space they are touring. During the tour (in the borderzone), the guide uses at least three tactics to help the tourist 'become local.' If the guide is successful, the tourist will end the tour (cross the other side of the border) with a new knowledge and the cultural cues to avoid 'looking like a tourist.' Unlike Bruner's tourists on safari, the domestic walking tourists are likely to return to the place they are touring. Thus, in walking tourism, there is less emphasis on 'peak experiences' and more focus on how it "takes about three hours to become a New Yorker"27 or how one can "become a real Chicagoan in no time."

Like Bruner's Maasai, urban tour guides are locals who come out to meet the tourists within the borderzone encounter. However, unlike the Maasai who conclude each performance having brought their tourists to the end of the borderzone, the urban walking tour guides deliver their tourists across it. While promotional advertisements in Kenya may suggest that the tourists will see the real Maasai, there is certainly no promise that they will become a 'real Maasai in no time.' This is a critical difference between the two types of tourism. For the Maasai (and Bruner), the borderzone is an in/out binary, whereas the walking tourists' experience changes drastically depending on the guide's facilitation and how they exit the borderzone_-did they 'become local' or are they still a tourist?

The borderzone in the original and current contexts, remains a creative space for the invention of culture. ${ }^{20}$ In a correctly facilitated borderzone crossing, cities and neighborhoods become constructed as comfortable and welcoming while notions of exclusion or unfamiliarity are dismantled..$^{22}$ The tourists must share common rituals, narratives, and practices with the toured community and distinguish themselves from true outsiders. ${ }^{38}$ Upon crossing the borderzone_-after 'becoming local'—the tourists are happy, thank the guide, and are amiable and optimistic about any future interaction in the city, even if they are only staying for dinner. When the promise to become a 'real Chicagoan' is unfulfilled, tourists react differently. They might be combative or disengaged, talking amongst themselves and disrespecting the guide. In order to successfully facilitate the transition, the guide must correctly employ the tactics of agent alignment, urban alchemism, and material action.

\section{Agent Alignment}

At the beginning of a typical walking tour, multiple culture-groups are represented: the tourist, the toured, and the guide who skillfully mediates the interactions. The guide is the critical force, facilitating the crossing between local and tourist status. Guides have previously been compared to parents who socialize their children, the tourists. ${ }^{39}$ While this metaphor may be patronizing to the walking tourist, guides certainly do 'raise' tourists into another world. The personalities and training of each individual guide will change the nuance of her presentation, ${ }^{40}$ however the overall alignment must not change. The successful guide needs to be an agent of the borderzone, carefully aligned as a third culture intermediary who can act with the babitus of the toured but who also is dedicated to transmitting knowledge. ${ }^{21}$ Guides are those who 'go-between' cultures and borders, ${ }^{40,41}$ facilitating the tourists' transitions to 'inside dopesters. ${ }^{24}$ Guides must appear to be passionate advocates for both the toured and the tourists' causes. ${ }^{32}$

The agent must demonstrate competence in the "culture of the toured.' In most cases the toured do not get to speak for themselves, rather the guide funnels thousands of voices, dead and alive, to create one exciting, if not untrue story. Oftentimes, the guide is the singular adjudicator deciding which narratives get relayed and which are left out. ${ }^{30}$ Tourists trust the guide's information to be accepted as cultural currency in the wider community. However, if the guide aligns too closely with the "culture of the toured," by only rattling off his knowledge of place, he may be perceived as simply showcasing his home and neglecting the promise of 'becoming local.' The walking tour guide is a curator as much as he is an entertainer and an educator. ${ }^{24}$ He directs the tourist gaze toward certain narratives and away from others, using linguistic devices like, "And I think it's so interesting, "It's very interesting, isn't it," "Now this is the most fantastic story," and "Anyhow, it's a great story."32 The guide must be friendly with the tourists and demonstrate that she understands their concerns and will support them as they enter an unfamiliar environment. ${ }^{41}$ However, if the guide steers too close to the "culture of the tourists" she may be perceived as lacking insider knowledge about the toured community and thus fail to facilitate the borderzone crossing.

\section{Urban Alchemism}

The second tactic walking tour guides use to transition tourists across the borderzone is urban alchemy. This term originates with Jack Katz who describes it as, "the trick of selling versions of the public to the public." 42 For Katz, the cityscape is presented for all to observe but only for some to appropriate. ${ }^{42}$ Wynn adapts the concept for the study of walking tourism, describing it as the utilization of space to create narrative and, especially, using leftover space to make a career. ${ }^{30}$ Wynn's comprehensive study on New York walking tour guides aligns with the current study: guides are often not corporate or bureaucratic cogs, but rather active constructors in what counts as the "culture of the toured." Many walking tour guides are on a mission to tell a forgotten part of 
their city's history. Wynn labels these guides, 'urban alchemists;' they re-enchant public space that city governments or bodies of authentication may have neglected. ${ }^{30}$ To make leftover and less obvious spaces important to tourists, guides intuitively use MacCannell's method of sight sacralization (naming, framing, elevating, enshrinement, reproduction) which transforms background or seemly mundane elements of the urban landscape into noteworthy sites. ${ }^{43,32}$ After a site is sacralized--given a story and meaning-- it transforms (alchemy) from being leftover space to becoming important to the story of the city. Urban alchemy also challenges the privatization of public space by leading tourists into the otherwise non-accessible public and private territory. ${ }^{16}$, ${ }^{30,41}$ Guides reclaim the street-level public stories and connect them to larger historical forces with an enthusiasm that aims to transform and enlighten the eager tourists. There is a certain irony that tourists, in this case, pay to walk in (usually) public space yet the guides see themselves as reenchanting the urban commons. ${ }^{44}$

Guides typically bind disparate sites together into a metanarrative in order to convey official and folk knowledge about the neighborhood, the city, and how to be local. ${ }^{21}$ They frame the route of the tour within a larger context, some kind of point they want to make about Chicago and its residents. Guides take physical spaces and cultural imaginaries and turn them into consumable and compact narratives, a type of shorthand that the tourist can use to conceptualize and conduct herself within the larger local community. Metanarratives here are different from Bruner's metanarratives, which are ideas that travel unknowingly with the tourist, a type of taken for granted assumption. ${ }^{20}$ Rather, here, they are conceptually closer to his 'tourist tales' which denotes how tourists recall their trip. ${ }^{20}$ However, the walking tour guide's metanarratives of urban alchemy are more pedagogical than personal, and are conceptually absent in much of the literature.

\section{Material Action}

The third tactic guides use to facilitate the borderzone crossing is material action, which encompasses physicality and materialist consumption. Tourists must enter, replicate, and consume the "culture of the toured." This concept is related to Cohen's guide animation which also involves using physicality to enhance the tourism experience. ${ }^{41}$ However, material action has a greater symbolic value than simply animating the tourist to increase their excitement. Material action must always be an embodied representation of the symbolic borderzone crossing taking place on tour.

Guides use a variety of physical experiences to prove that the promise of 'becoming local' is being fulfilled. One of the most common methods involves enshrined sites-- sites housed within larger sites. ${ }^{14}$ By leading tourists to an enshrined site, the guide ensures that the group will cross numerous smaller, often real, borders (thresholds). As tourists comfortably cross these thresholds to observe what is within, they share experiences with locals entering the same spaces to see the enshrined treasure. Fine and Speer believe that such movement across thresholds creates a ritual transformation in which 'segregated tourists' become part the host community through the shared experiences. ${ }^{32}$ This transfer of cultural capital and co-existent habitus is exactly what the tourists paid for and were promised.

Material action can also include food consumption (see below) or something as seemingly insignificant as removing the sticker or pin that was attached to one's clothing at the beginning of the tour. ${ }^{27}$ Tourists may also replicate the materiality of their experience through photographs. While picture taking is a quintessential tourist activity, tourists who realize they are not getting across the borderzone seem to take fewer photographs than tourists who are in the process of 'becoming local.' One could speculate that the tourists who are 'becoming local' might understand that they will soon need to shed the tourist babitus, so they take an increased number of photographs. Alternatively, they might just be enjoying the tour more than those who are not on the path to 'real Chicagoan.' Regardless of the specific methods encouraged by the guide, by the end of a tour successful material action and physical engagement is required for the tourists to garner the experiences needed to cross the borderzone.

\section{Case 1: A cautionary tale from Pilsen}

Touring ethnic neighborhoods has been a middle class White American pastime since the 1920s. ${ }^{45}$ While 'slumming' -or cautiously gazing at poverty while pretending not to-was a feature of the London upper class, urban and suburban White Americans openly and unabashedly ogled at the 'exotic' enclaves of newly arrived groups from around the world. 22,46 'These Americans were less eager to see class difference and more interested in essentialized ethnicities. Today, tourists can still wander an 'imagined Orient in miniature' in Chicago's neighborhoods, complete with Orientalist discourse. ${ }^{22,47}$ The stereotypes are persistent, especially in a city as racially segregated as Chicago 48 where dominant groups can make every effort to avoid seeing who they might consider 'Third World peoples' in the city, (even as they jet set off to Bangkok or Nairobi). ${ }^{20}$

Walking tour guides, the urban alchemists, control some amount of discourse about these racialized communities. It is undeniable that tourism reinforces dominant imaginaries and legitimizing rationales. ${ }^{22}$ While it is undoubtedly problematic, often exploitative, for guides to overlay their own narratives of place, ${ }^{49}$ the walking tour can open a small window for counter-hegemonic stories to be told. It is possible for guides to contest normative assertions or stereotypes and such re-framings can lead to the best tours and most engaged tourists. ${ }^{30}$ It is possible to use the voices from the community to break dichotomies-not to advocate for 
colorblindness - but to truly unpack what it means to live in a multicultural, hyper-segregated, metropolis and how social and historical factors have caused and continue to maintain an inequitable situation. ${ }^{22,50}$ Surely, to become a 'real Chicagoan,' one cannot ignore the neighborhoods, which even the official tourism website points to as the 'heart and soul' of the city. ${ }^{51}$ 'The walking tourist should not, however, take essentialized divisions at face value, ${ }^{52}$ even if such acritical acceptance is a quality of many real Chicagoans.

It is within this social context and complicated history that Fred, who is not a resident of Pilsen or a Latino person, enters the borderzone with his tourists. Things first went awry when Fred chose to align himself with what he perceived to be the "culture of the toured," rather than as an agent of the borderzone. Since Fred lived in the same area as the tourists, he tried to renegotiate himself as one of them. He knew that everyone on the tour was affiliated with the Catholic Church, so he made liberal reference to his Catholic faith. In order to align himself with the tourists, Fred would joke about rivalries within local Catholicism: "How do you feel about those people who go to [a rival church]? We hate 'em. Even we Catholics, we don't like people from the other side. Isn't that insane, it's not what our faith is based on." This rhetoric ended up creating a dichotomy between the Pilsen Catholic community (Latino/a) and the suburban Catholic community (White).

When discussing White Catholics, Fred easily uses "we.” However, when describing Pilsen residents, he often used third person pronouns and "Mexicans," (even though Mexican-Americans would be more accurate). When presenting the National Museum of Mexican Art, he said, "they want to invite people to be invited to the culture," when talking about the pre-fire housing of Pilsen, he said, "Look at these houses! Would you see these in Mexico? I've never been to Mexico, you tell me." Even when Fred tried to speak as a learned authority on Pilsen culture, he produced awkward, stereotypical phrases constructed from an outsider's lens: "in the Mexican culture, the mother image is huge," or "the good Mexican male, you gotta be the tough guy." While this effort may have increased his connection with the tourists, it pushed him further from being able to deliver them across the borderzone. The plastic three-ring binder of answers to common Pilsen questions that Fred carried and referenced at almost every stop might have given the tourists a more nuanced presentation of the neighborhood and would have lacked Fred's intermittent, often incorrect, interpretation.

Fred's urban alchemy spun the metanarrative of preservation versus progress which, according to him, was one of the major issues facing communities like Pilsen (as if they are somehow pre-modern). Again, Fred constructed a dichotomous narrative that implied the gears of modernity (Whiteness) could not co-exist with the historical (Latino/a). Near the end of the tour, the group stopped outside of the home of internationally-renowned artist Hector Duarte. The house has a colorful two-story mural of a man casting off his chains painted onto an exterior wall. For Fred, this site was the epitome of his metanarrative. He turned to the tourists and asked if such a mural would be appropriate in their neighborhood. When they shook their heads, he told them that it probably was also technically illegal in Pilsen; however, "maybe it's against some city regulation, but they let it slide because it's important to the neighborhood." Probably unwittingly, Fred neutralized White culture as the monotonous output of modernity while positioning the Latino artist as someone with a culture so strong that it can bypass city ordinances. While this is problematic enough on its own accord, the continued dichotomy also meant that the tourists were not collecting a cultural currency that would be accepted in wider-Pilsen.

For material action, Fred showed the tourists the shrine to Our Lady of Guadalupe which is housed in St. Pius Church. Fred offered little commentary about the church or its role in the development of the neighborhood, but did emphasize the ritual of taking holy water before entering. While this signaled his comfort crossing thresholds in $a$ church, he was clearly out of place here. In that moment, the church-goers were all older, quiet Latino men, not loud Irish-Catholic tour guides. Thus, even Fred's movement into semi-public space only served to highlight his inability to help his tourists become any closer to 'real Chicagoans' than they were at the start of the tour.

The tourists seemed to recognize this failure to facilitate the crossing. They were polite but inattentive at the beginning of the tour and only became more disconnected throughout the day. This eventually culminated into two major challenges to Fred. In the first, he argued with a tourist over her multi-racial identity and in the second another tourist boldly corrected Fred's (incorrect) spelling of "Czech." The tour ended without any borderzone exit ritual or rhetoric. Certainly, the tour took place in a challenging social milieu and the debate can be had over the appropriateness of such a tour even existing. However, it is also apparent that Fred's poor utilization of agent alignment, urban alchemy, and material action contributed to the exceptional problems he faced.

Case 2: A borderzone crossing

From the beginning of the downtown Loop tour, Alex positioned himself as an insider: he told the tourists that he used to work in the Cultural Center, was dressed in slacks which are commonplace in the Loop, and carried a Chicago Architecture Foundation bag around his shoulder. First, Alex told the tourists how much he loved walking in the city and how his job with Out and About allowed him to spend time simply being outdoors. This language probably reassured the tourists that Alex, like them, enjoys 
gazing and consuming; he is not so local that he forgets to appreciate the sites. The tourists seemed to trust him as a cultural liaison: they believed in his abilities to move them from Mississippians to 'real Chicagoans.'

Not ten seconds after stepping out of the Cultural Center onto the sidewalk, Alex unexpectedly stopped the group. He beckoned for the tourists to huddle around a lamppost and pointed to a metal stamp design only a few inches in diameter. Alex told the group that it was Chicago's municipal device and after explaining the symbolism of the design, revealed that it could be found hidden in plain sight on most city buildings and structures. According to Alex, many Chicagoans never notice the stamp on mundane items, like lampposts. In this pedagogical moment, Alex aligned himself both as an expert with a keen eye and as an instructor with a desire to transmit cultural capital.

Alex's metanarrative was that Chicago is a city in a garden. The familiar slogan dates back to the city's first planners and Alex reinforced it as a local and proud narrative of Chicago. A significant portion of the Loop tour did occur within the boundaries of public parks and Alex noted, "as much green space as you can fit into a city, Chicago tries to do that." He often presented sites as special opportunities to see more of the city and the gardens. For example, Alex told the group to, "swing through the garden, because I want you to see an art piece." Not only does this reinforce the metanarrative, it also highlights his ability to utilize public space within the narrative. The implications of his statement are clear, without a guide, the tourists would miss a part of Chicago that could help them 'become local.' As Alex stood with his tourists in front of a popular outdoor art installation, the boundaries between tourists photographing the art and real Chicagoans photographing the art began to blur.

Alex's material action featured the enshrined Tiffany domes of the Cultural Center. Alex noted that the Cultural Center is, "well publicized now but used to be a hidden gem" and that it holds, "colossal, impressive, expensive treasures." The glass domes in the ceiling are easily missed if one does not look up at the right moment. When Alex shouts, "come with me I want to show you something special," before showing the tourists where to stand to see the one small piece of untarnished Tiffany glass within the dome, he is actively helping the tourists cross the borderzone.

However, his most effective utilization of material action involved food. The Loop tourists passed a Garrett's Popcorn shop, a well-known institution in Chicago. One of the tourists shouted, "someone told me no matter how long the line is, wait for it." Upon hearing this, Alex stopped the tour and used his allotted funds to buy a bag of popcorn for the group to share. Before giving it to them, he joked, "Now, nobody has an addictive personality, right?" Because the tourists had heard about Garrett's Popcorn from others who had gained 'local' status in Chicago, this moment was especially impactful in their transition across the borderzone. This physicality, eating expensive popcorn, symbolized the greater consumption of the Chicago imaginaries taking place on tour.

Alex concluded his Loop tour with all the tourists circled up in a seemingly random aisle of Macy's. After thanking them for visiting Chicago, he paused. Seeming to remember one last thing, he quietly told the group, "look up." Above their heads was yet another Tiffany glass dome, one of the largest in the city. The tourists stood in awe, they thanked Alex, knowing they never would have found this treasure on their own. Alex responded, "sometimes you just have to be a dumb tourist and just look up, it's the key to enjoying Chicago." This was more than a 'big reveal' at the end of the tour, Alex's dialogue gave the tourists permission to occasionally cross back into the borderzone to be tourists. In effect, this legitimized their acquired cultural knowledge and verified that they must have become 'real Chicagoans' as promised.

\section{CONCLUSIONS}

While these two tours were quite different, they are good examples of agent alignment, urban alchemy, and material action as conceptualized in this study implemented well and poorly. While Fred's troubles did not emanate solely from his difficulties with the borderzone tactics, failing to utilize them well contributed to the ongoing problems. Like the safari tourists Bruner observed, Fred's tourists exited the borderzone without 'becoming local.' This is not standard form for walking tours which attempt to be more grounded and pedagogical than other types of cultural tourism, such as cultural theme parks or bus tours. In contrast, Alex skillfully guided his tourists through the Loop and completed the tour with a rhetorical flourish validating their newfound localness and (perceived) Chicago habitus.

This study was limited (there can always be more participant observation), but proposes a grounded theory of borderzone tactics, reaffirms the unique qualities of walking tourism, and advances the conversation on the pedagogical nature of tourism more broadly. There may be other borderzone tactics for future research to identify. Additionally, more in-depth research into counterhegemonic guiding narratives within racialized communities could have wide appeal both in the academic and guiding communities. Future scholars may also follow up with tourists to understand how they value and implement their new 'local habitus' after the walking tour concludes. 


\section{ACKNOWLEDGMENTS}

The author thanks Dr. Connie Mixon and Dr. Mike Lindberg at Elmhurst College, Keji Kujjo at Bowling Green, and the people of the pseudonymous tour company in Chicago for their critical contributions to this project. Portions of this project were presented at the Elmhurst College Research Showcase (2016) and the Aldrich Conference in St. John's, Newfoundland (2017).

\section{REFERENCES}

1. Hewitt, E. (n.d.) Tourist No More: Three Secrets for Traveling like a Local, IndependentTraveler.com, bttp:/ / www.independenttraveler.com/travel-tips/travelers-ed/tourist-no-more-three-secrets-for-traveling-like-a-local (accessed Oct 2016)

2. Hoeller, S. C. (2015) 10 Travel Apps That Will Make You Feel Like a Local, Time Magazine, http://time.com/4023144/travelapps-feel-locall (accessed Oct 2016)

3. LikeALocalGuide.Com (2016) Chicago City Guide, https:// wmw.likealocalguide.com/ chicago, (accessed Oct 2016)

4. Bourdieu, P. (1986) The Forms of Capital, in Handbook of Theory of Research for the Sociology of Education (Richardson, J. E., Ed.) 241-258. Greenwood Press, New York.

5. Crick, M. (1989) Representations of International Tourism in the Social Sciences: Sun, Sex, Sights, Savings, and Servility, Annual Review of Anthropology 18: 307-344.

6. Bourdieu, P. (1995 [1977]) Outline of Theory and Practice (trans. Nice, R.) Cambridge University Press, Cambridge.

7. Gillespie, A. (2006) Tourist photography and the reverse gaze, Ethos 34(3): 343-366. doi:10.1525/eth.2006.34.3.343

8. Broad, S. (2003) Living the Thai Life-A Case Study of Volunteer Tourism at the Gibbon Rehabilitation Project, Thailand, Tourism Recreation Research 28(3): 63-72. doi:10.1080/02508281.2003.11081418

9. Office of the Mayor of Chicago, Mayor Emanuel and Choose Chicago Announce Record Tourism in 2015, bttps:/ / www.cityofchicago.org/content/dam/ city/depts/mayor/Press\%20Room/Press\%20Releases/2016/April/4.26.16MayorChooseChicagoA nnounceRecordTourism.pdf (accessed April 2017)

10. National Travel and Tourism Office, Overseas Visitation Estimates for U.S. States, Cities, and Census Regions, 2015, bttp:/ / travel.trade.gov/outreachpages/download data table/2015 States and Cities.pdf (accessed April 2017)

11. Bernard, H. R. (2006) Research Methods in Anthropology $4^{\text {th }}$ ed., AltaMira, Lanham, MD.

12. Berreman, G. D. (2007) Behind Many Masks: Ethnography and Impression Management, in Ethnographic Fieldwork (Robben, A. C. G. M., Sluka, J. A., Eds.) Blackwell, Malden, MA.

13. Staddon. S. (2014) So What Kind of Student Are You? The Ethics of 'Giving Back' to Research Participants, in Fieldwork in the Global South: Ethical Challenges and Dilemmas (Lunn, J., Ed.) 249-261, Routledge, New York.

14. MacCannell, D. (2013 [1976]) The Tourist: A New Theory of the Leisure Class. University of California Press, Berkeley, CA.

15. Gottlieb, A. (1982) American's Vacations, Annals of Tourism Research 9: 165-187. doi:10.1177/004728758302200166

16. Urry, J. (1990) The Tourist Gaze Sage, London.

17. Cohen, E. (1979) A Phenomenology of Tourist Experiences, Sociology 13(2): 179-201. doi:10.1177/003803857901300203

18. Bruner, E. M. (1994) Abraham Lincoln as Authentic Reproduction: A Critique of Postmodernism, American Anthropologist 96(2): 397-415. doi:10.1525/aa.1994.96.2.02a00070

19. Bruner, E. M. (2001) The Maasai and the Lion King: Authenticity, Nationalism, and Globalization in African Tourism, American Ethnologist 28(4): 881-908. doi:10.1525/ae.2001.28.4.881

20. Bruner, E. M. (2005) Culture on Tour University of Chicago, Chicago.

21. Wynn, J. (2011) Elective Affiliations: Marginal Urban Characters Negotiating Legitimacy and Autonomy in Urban Culture, International J of Social Inquiry 4(1), 133-157.

22. Santos, C. A., Belhassen, Y. and Caton, K. (2008) Reimagining Chinatown: An analysis of tourism discourse, Tourism Management 29: 1002-1012. doi:10.1016/j.tourman.2008.01.002

23. Butcher, J. (2003) The Moralisation of Tourism: Sun, sand . . and saving the world? Routledge, New York.

24. Schmidt, C. J. (1979) The Guided Tour: Insulated Adventure, Urban Life, 7(4), 441-467. doi:10.1177/089124167900700402

25. Nash, D. (1989) Tourism as a Form of Imperialism, in Hosts and Guests: The Anthropology of Tourism, (Smith, V., Ed.) 37-52, University of Pennsylvania Press, Philadelphia.

26. Wynn, J. R. (2007) Field Note: Guiding Ideas, Contexts 6: 56-57.

27. Wynn, J. R. (2005) Guiding Practices: Storytelling Tricks for Reproducing the Urban Landscape, Qualitative Sociology 28(4), 399-417. doi:10.1007/s11133-005-8365-2

28. Higgins-Desbiolles, F. and Powys Whyte, K. (2013) No High Hopes for Hopeful Tourism: A Critical Comment, Annals of Tourism Research 40: 428-433. doi: 10.1016/j.annals.2012.07.005 
29. Lopez, E. M. (1980) The Effect of Leadership Style on Satisfaction Levels of Tour Quality, J of Travel Research 18(4): 20-23. doi:10.1177/004728758001800403

30. Wynn, J. R. (2010) City Tour Guides: Urban Alchemists at Work, City \& Community 9(2), 145-164. doi:10.1111/j.15406040.2010.01322.x

31. MacCannell, D. (1973) Staged Authenticity: Arrangements of Social Space in Tourist Settings, Am J of Sociology 79(3): 589-603.

32. Fine, E., and Speer, J. H. (1985) Tour Guide Performances of Sight Sacralization, Annals of Tourism Research 12, 73-95. doi:10.1016/0160-7383(85)90040-4

33. Cohen, E, and Cohen, S. A. (2012) Authentication: Hot and Cold, Annals of Tourism Research 39(3): 1295-1314. doi:10.1016/j.annals.2012.03.004

34. Bruner, E. M., and Kirshenblatt-Gimblett, B. (1994) Maasai on the Lawn: Tourist Realism in East Africa, Cultural Anthropology 9(4): 435-470. doi:10.1525/can.1994.9.4.02a00010

35. Obrador, P. and Carter, S. (2010) Art, politics, memory: Tactical Tourism and the route of anarchism in Barcelona, Cultural Geographies in Practice 17(4): 525-531. doi:10.1177/1474474010368610

36. MacCannell, D. (2001) Remarks of the Commodification of Cultures, in Hosts and Guests Revisited: Tourism Issues of the 21st Century (Smith, V. L., and Brent, M., Eds.) 380-390 Cognizant Communication, New York.

37. Dann, G. (1996) The Language of Tourism: A Sociolinguistic Perspective, CABI, Wallingford.

38. McCallion, M. J. (2007) In-Groups and Out-Groups, in Blackwell Encyclopedia of Sociology (Ritzer, G., Ed.) Blackwell Reference Online. doi:10.1111/b.9781405124331.2007.x

39. Schuchat, M. G. (1983) Comfort of Group Tours, Annals of Tourism Research 10, 465-477. doi:10.1016/0160-7383(83)90003-8

40. Tsaur, S., and Teng, H. (2017) Exploring tour guiding styles: The perspective of tour leader roles, Tourism Management 59: 438448. doi:10.1016/j.tourman.2016.09.005

41. Cohen, E. (1985) The Tourist Guide: The Origins, Structure and Dynamics of a Role, Annals of Tourism Research 12, 5-29. doi:10.1016/0160-7383(85)90037-4

42. Katz, J. (2010) Time for new urban ethnographies, Ethnography 11(1): 25-44. doi:10.1177/1466138109346999

43. MacCannell, D. (2004). Sightseeing and Social Structure: The Moral Integration of Modernity, in Tourists and Tourism: A Reader (Gmelch, S. B., Ed.) 55-70 Waveland Press, Long Grove, IL.

44. Harvey, D. (2012) Rebel Cities, Verso, London.

45. Graburn, N. H. H. (1983) The Anthropology of Tourism, Annals of Tourism Research 10: 9-33. doi:10.1016/01607383(83)90113-5

46. Stienbrink, M. (2012) 'We did the Slum!' - Urban Poverty Tourism in Historical Perspective, Tourism Geographies 14(2): 213234. doi:10.1080/14616688.2012.633216

47. Said, E. W. (2003 [1978]) Orientalism 25th Anniv. ed., Vintage Books, New York

48. Bowean, L. (2016). Segregation declines in Chicago, but city still ranks high, census data show, Chicago Tribune (4 Jan), bttp:/ / www.chicagotribune.com/ news/ct-segregation-declines-neighborhoods-change-met-20160103-story. btml

49. Conforti, J. M., (1996) Ghettos as Tourism Attractions, Annals of Tourism Research 23(4): 830-842. doi:10.1016/01607383(96)00010-2

50. Dyson, P. (2012) Slum Tourism: Representing and Interpreting 'Reality' in Dharavi, Mumbai, Tourism Geographies, 14(2), 254274. doi:10.1080/14616688.2011.609900

51. Choose Chicago, Discover Chicago Neighborhoods, http:/ / www.choosechicago.com/neighborboods-and-communities/ (accessed April 2017)

52. Wolf, E. (1982) Europe and the People Without History University of California Press, Berkeley, CA.

\section{ABOUT THE AUTHOR}

Jacob Henry received his B.A. in Sociology and Intercultural Studies from Elmhurst College in 2016. This work was completed as part of his independent intercultural research. He is currently pursuing an M.A. in anthropology at Memorial University of Newfoundland where he studies tourists who teach and teachers who tour, especially in southern Africa.

\section{PRESS SUMMARY}

Has a friend ever come back from vacation and said, "I really felt like a local?" It wouldn't be surprising, given that there are plenty of resources devoted to making travel more local-like. It seems everybody wants to avoid looking like a tourist. This paper explains the tactics walking tour guides in Chicago utilize to make you feel like a local. After reading this paper, you will know what to look for when guides are employing the rhetorical and symbolic methods that help you feel connected and invested in a new place. 